\title{
Serotonin Transporter Polymorphism Mediates Vulnerability to Loss of Incentive Motivation Following Acute Tryptophan Depletion
}

\author{
Jonathan P Roiser*,1,2, Andrew D Blackwell', Roshan Cools ${ }^{3,4}$, Luke Clark ${ }^{4}$, David C Rubinsztein ${ }^{5}$, \\ Trevor W Robbins ${ }^{4}$ and Barbara J Sahakian' \\ 'Department of Psychiatry, Addenbrooke's Hospital, Cambridge, UK; ${ }^{2}$ Department of Imaging Neuroscience, Institute of Neurology, London, UK; \\ ${ }^{3}$ Helen Wills Neuroscience Institute, University of California, Berkeley, CA, USA; ${ }^{4}$ Department of Experimental Psychology, Institute for Medical \\ Research, Cambridge, UK; ${ }^{5}$ Department of Medical Genetics, Cambridge Institute for Medical Research, Addenbrooke's Hospital, Cambridge, UK
}

\begin{abstract}
The serotonin (5-HT) system is implicated in incentive motivational processes. The present study utilized the acute tryptophan depletion (ATD) procedure to investigate the effect of temporarily lowering 5-HT synthesis on motivation in healthy volunteers, stratifying the results by allelic variation at the serotonin transporter gene (5-HTTLPR). ATD resulted in a robust reduction in plasma tryptophan concentration. Consistent with a previous study, ATD attenuated motivationally speeded action on the Cued-Reinforcement Reaction Time task. The present investigation revealed that this effect was restricted to volunteers of the ss genotype, whereas $/$ volunteers exhibited intact motivationally speeded action following ATD (treatment $\times$ reinforcement probability $\times$ genotype interaction: $F_{1,26}=5.8$, $p=0.024)$. Furthermore, tryptophan availability to the brain was correlated positively with motivationally speeded action following ATD in the ss genotype group $\left(\rho_{13}=0.7 \mathrm{I}, p=0.006\right)$, whereas this correlation was negative in the $/ 1$ genotype group $\left(\rho_{14}=-0.60\right.$, $p=0.023$ ). This is the first study to suggest that allelic variation at the 5-HTTLPR mediates motivational responses to ATD in healthy volunteers. These data indicate that the s allele at the 5-HTTLPR may confer risk for depression via its effect on incentive motivational processing, and highlight the importance of genetic variation in determining individual responses to pharmacological treatments. Neuropsychopharmacology (2006) 31, 2264-2272. doi:I0.I038/sj.npp. I 30 I055; published online I5 March 2006
\end{abstract}

Keywords: serotonin; acute tryptophan depletion; serotonin transporter gene (5-HTTLPR); reward; motivation; depression

\section{INTRODUCTION}

The serotonin (5-HT) system is well known to affect incentive motivational processes. Enhancement of 5-HT function reinstates brain electrical self-stimulation following drug withdrawal (Harrison et al, 2001), and the presentation of reward-associated cues results in an increase in 5-hyroxyindole acetic acid (5-HIAA; the major metabolite of 5-HT) (Merali et al, 2004). Furthermore, the reinforcing properties of cocaine are enhanced by chronically increased 5-HT levels, while being attenuated following 5-HT depletion (Aronson et al, 1995; Sasaki-Adams and Kelley, 2001). It is possible that 5-HT influences reward processing via its interaction with the mesolimbic dopamine

*Correspondence: Dr JP Roiser, Department of Imaging Neuroscience, Institute of Neurology, Room 807, Queen Square House, Queen Square, London, WCIN 3BG, UK, Tel: + 4420783736 I I ext. 427I, Fax: + 44207676205 I, E-mail: j.roiser@ion.ucl.ac.uk

Received I November 2005; revised 13 January 2006; accepted 20 January 2006

Online publication: I February 2006 at http://www.acnp.org/citations/ Npp020 106050657/default.pdf
(DA) system, since DA signalling in the substantia nigra and ventral tegmental area are dramatically reduced following 5-HT depletion (Minabe et al, 1996).

In humans, 5-HT synthesis can be temporarily reduced by the administration of an amino-acid mixture selectively lacking in tryptophan, a technique known as acute tryptophan depletion (ATD). The best-known effect of ATD is to temporarily reinstate depressive symptoms in patients recovered from depression (Delgado et al, 1990; Leyton et al, 2000; Smith et al, 1997). In addition, it was recently demonstrated that ATD abolished motivationally speeded action on a novel reaction time task in healthy volunteers (Cools et al, 2005), while Rogers et al (2003) reported reduced discrimination between possible gains on a gambling game following ATD.

Individual subjective and behavioral responses to psychopharmacological interventions have been associated with allelic variations at polymorphic sites in genes regulating the activity of the monoamine systems, polymorphisms that are also implicated in conferring risk for psychiatric disorders (Lott et al, 2005; Mattay et al, 2003; Neumeister et al, 2002). One such polymorphism is the 
5-HT transporter (5-HTT)-linked polymorphic region (5HTTLPR), a 44 base-pair insertion/deletion polymorphism in the promoter region of the gene coding for the 5-HTT that results in two common alleles, termed 'short' $(s)$ and 'long' (l) (Heils et al, 1996). The $s$ allele has been associated with increased risk for depression (Caspi et al, 2003; Furlong et al, 1998) and poorer responses to selective serotonin reuptake inhibitor (SSRI) treatment in depressed patients (Smeraldi et al, 1998). The $s$ allele has also been associated with attenuated prolactin responses to fenfluramine (Reist et al, 2001) and SSRIs (Smith et al, 2004; Whale et al, 2000) in healthy volunteers, suggestive of reduced extracellular 5-HT function.

Consistent with this hypothesis, Neumeister et al (2002) reported that a group of $s$ allele carrying women with no history of depression were more vulnerable to mood change following ATD compared to $l l$ homozygotes. However, the effect of allelic variation at the 5-HTTLPR on response to ATD is complex and appears to interact with past diagnosis, since it has also been reported that patients recovered from depression of the $l l$ genotype were more vulnerable to an increase in depressive symptomology than those carrying the $s$ allele (Moreno et al, 2002).

\section{Study Design and Hypotheses}

In the present study we examined the effect of ATD incentive motivation in healthy volunteers, assessing behavior on a test of reward processing in individuals of $l l$ and ss genotypes at the 5-HTTLPR. As previous studies have suggested that reducing 5-HT impairs reward processing (Cools et al, 2005; Rogers et al, 2003), and ss individuals show reduced functional responsivity of the 5-HT system (Smith et al, 2004), we hypothesised that the ss genotype group would demonstrate impaired reward processing following ATD relative to the $l l$ genotype group.

\section{MATERIALS AND METHODS}

\section{Participants}

This study was carried out in two phases, each with its own informed consent process. Initially, volunteers were recruited by advertisement in the community. Approximately 150 participants responded to the advertisement and were invited to attend an initial screening session (Phase I), where they were administered a general health questionnaire, including a section on psychiatric disorders and the Beck Depression Inventory (BDI) (Beck et al, 1961). The health questionnaire included questions concerning past treatment with antidepressants, anxiolytics, antipsychotics and any other medication (including for nonpsychiatric complaints), as well as questions concerning diagnosis of all major psychiatric disorders. A $10 \mathrm{ml}$ blood sample was taken, from which DNA was extracted in order to determine 5-HTTLPR genotype. All participants completing Phase I were compensated $£ 7$ for their time and travel expenses. The study was approved by the Cambridge Local Research Ethics Committee (LREC No. 03/266), and all participants gave informed consent, including a section consenting to the storage of their DNA and contact details. We then genotyped all individuals for 5-HTTLPR polymorphism and contacted those volunteers homozygous for either the $s$ or the $l$ allele (ie heterozygous participants were not tested in Phase II). We employed this strategy in order to maximize the potential differences between the genotype groups, since it is not clear whether the $s$ allele exerts a dominant or co-dominant effect. Inclusion criteria for the tryptophan depletion study (Phase II) were $l l$ or ss genotype at the 5-HTTLPR. Exclusion criteria were any history of Axis I psychiatric disorders, as assessed by the questionnaire, including any treatment for depression or anxiety disorders; a score greater than 9 on the BDI; any history of neurological illness or closed head injury; any history of drug or alcohol dependence. Approximately 50 volunteers who attended the screening session satisfied the inclusion and exclusion criteria and were invited to take part in Phase II. None of the volunteers included in the present study participated in our previous investigation (Cools et al, 2005).

\section{Experimental Procedure - Acute Tryptophan Depletion (Phase II)}

All participants were informed of the details and procedure of Phase II either by telephone or at the screening session. All participants attending Phase II provided informed consent, were compensated $£ 35$ for their time and travel expenses for each testing day completed, and the study was approved by the Cambridge Local Research Ethics Committee (LREC No. 03/338). Participants attended two testing sessions in a double-blind placebo-controlled crossover design. Testing sessions were separated by at least 1 week in order to avoid carryover effects. Participants arrived at the Addenbrooke's Centre for Clinical Investigation at approximately 0830 hours having fasted from 2400 hours the previous night, drinking only water. Following baseline measurements of mood and a $10 \mathrm{ml}$ blood sample, at 0900 hours $\left(\mathrm{T}_{0}\right)$ participants were administered either a balanced amino-acid drink $(\mathrm{TRP}+)$ or the same mixture with the absence of tryptophan (TRP-) (for constituents see below). The amino acids were dissolved in approximately $300 \mathrm{ml}$ tap water and mixed with cherry vanilla, lemon and lime or grapefruit flavor to improve palatability.

For the next $5 \mathrm{~h}$, participants rested at the research centre, and were allowed water ad libitum as well as decaffeinated tea or coffee (without milk). At 1200 hours participants were given a low-protein lunch of salad, crackers, jam and either an apple or an orange. At 1400 hours $\left(\mathrm{T}_{5}\right)$, a second $10 \mathrm{ml}$ blood sample was taken, participants' mood was assessed and a battery of neuropsychological tests, including the Cued-Reinforcement Reaction Time task (CRRT), was administered. Thirty volunteers completed Phase II, 15 of the $l l$ genotype ( 8 male, 7 female) and 15 of the ss genotype ( 9 male, 6 female). Female participants were not tested in the week before menses or during menstruation.

\section{Amino-Acid Mixtures}

The quantities of amino acids in each drink were based on those used by Young et al (1985), though a $75 \mathrm{~g}$ mixture was 
employed to minimise nausea. Amino-acid mixtures were as follows:

TRP + : L-alanine, $4.1 \mathrm{~g}$; L-arginine, $3.7 \mathrm{~g}$; L-cystine, $2.0 \mathrm{~g}$; Glycine, 2.4 g; L-histidine, $2.4 \mathrm{~g}$; L-isoleucine, $6 \mathrm{~g}$; L-Leucine, $10.1 \mathrm{~g}$; L-lysine, $6.7 \mathrm{~g} ; \mathrm{L}$-Methionine, $2.3 \mathrm{~g}$; L-proline, $9.2 \mathrm{~g}$; L-phenylalanine, $4.3 \mathrm{~g}$; L-serine, $5.2 \mathrm{~g}$; L-threonine, $4.9 \mathrm{~g}$; L-tyrosine, $5.2 \mathrm{~g}$; L-valine, $6.7 \mathrm{~g}$ and L-tryptophan, $3.0 \mathrm{~g}$ total $78.0 \mathrm{~g}$

TRP-: L-alanine, $4.1 \mathrm{~g}$; L-arginine, $3.7 \mathrm{~g}$; L-cystine, $2.0 \mathrm{~g}$; Glycine, $2.4 \mathrm{~g}$; L-histidine, $2.4 \mathrm{~g}$; L-isoleucine, $6 \mathrm{~g}$; L-Leucine, $10.1 \mathrm{~g}$; L-lysine, $6.7 \mathrm{~g} ; \mathrm{L}-M e t h i o n i n e, 2.3 \mathrm{~g}$; L-proline, $9.2 \mathrm{~g}$; L-phenylalanine, $4.3 \mathrm{~g}$; L-serine, $5.2 \mathrm{~g}$; L-threonine, $4.9 \mathrm{~g}$; L-tyrosine, $5.2 \mathrm{~g}$ and $\mathrm{L}$-valine, $6.7 \mathrm{~g}$ - total $75.0 \mathrm{~g}$

For female participants, the same ratios of amino acids were used, but with a $20 \%$ reduction in quantity to take into account lower bodyweight.

\section{Biochemical Measures}

Plasma was separated by centrifugation and stored at $-20^{\circ} \mathrm{C}$. Plasma total amino-acid concentrations (tyrosine, valine, phenylalanine, isoleucine, leucine and tryptophan) were measured by means of HPLC with fluorescence end-point detection and pre-column sample derivatization adapted from the methods of Furst et al (1990). Norvaline was used as an internal standard. The limit of detection was $5 \mathrm{nmol} / \mathrm{ml}$ using a $10 \mu \mathrm{l}$ sample volume, and inter- and intra-assay coefficients of variation were $<15$ and $<10 \%$, respectively.

\section{Genotyping}

Genotyping was performed using the polymerase chain reaction (PCR) protocol of Furlong et al (1998), using the primers stpr5: $5^{\prime}$-ggc gtt gcc gct ctg aat gc- $3^{\prime}$ and stpr3: $5^{\prime}$-gag gga ctg agc tgg aca acc ac- $3^{\prime}$. Successful amplification was achieved using an initial denaturing step at $95^{\circ} \mathrm{C}$ for $4.5 \mathrm{~min}$ followed by 35 cycles of $95^{\circ} \mathrm{C}$ for $30 \mathrm{~s}, 61^{\circ} \mathrm{C}$ for $30 \mathrm{~s}$, $72^{\circ} \mathrm{C}$ for $30 \mathrm{~s}$ and a final extension of $72^{\circ} \mathrm{C}$ for $10 \mathrm{~min}$. The $25 \mu \mathrm{l}$ reaction mixture consisted of $1 \mu \mathrm{LNA}$ (approximately 50-200 ng), $10 \mathrm{mM}$ Tris- $\mathrm{HCl}, 50 \mathrm{mM} \mathrm{KCl,} \mathrm{0.1 \%} \mathrm{Triton}{ }^{\circledR} \mathrm{X}$ 100, $1.5 \mathrm{mM} \mathrm{MgCl}$, 5\% DMSO, $200 \mu \mathrm{M}$ dNTPs (including dGTP/7-deaza dGTP $1: 1$ ), $100 \mathrm{ng}$ of each primer and 0.5 units Taq polymerase at $\mathrm{pH}$ 9.0. Products were analyzed on $2 \%$ agarose gels stained with ethidium bromide.

\section{Cued-Reinforcement Reaction Time Task (CRRT)}

The CRRT is a measure of incentive motivational processing that is sensitive to manipulation of the 5-HT system (Cools et al, 2005). On each trial subjects were presented with three horizontally adjacent circles ('circles-stimulus'). Within each of these three circles, a smaller circle was presented. Subjects were asked to identify the 'odd-one-out' circle. Responses were made by pressing, with the right index, middle or ring finger, one of three keys on an English keyboard (' $<$ ', ' $>$ ' or '?') corresponding to the location of the 'odd-one-out' circle.

Before the experimental block of 96 trials, two practice blocks of 20 trials were given, in which circles-stimuli were presented without feedback. Subjects were encouraged to respond as fast as possible without making any mistakes. A mean RT and standard deviation were extracted from the second practice block (provided the percentage of correct responses exceeded $85 \%$ ) and a cutoff score was calculated by subtracting the standard deviation from the mean RT.

On some experimental block trials feedback coincided with the response. Following a correct response, a green smiley face and an increase in total point score was presented in the center of the screen (for $500 \mathrm{~ms}$ ). Following an incorrect response a red sad face was presented. The number of points gained was dependent on accuracy and $\mathrm{RT}$, so that a fast correct response was rewarded with 100 points (and a flourish sound), a slow correct response with 1 point (and a short high-frequency tone), and an incorrect response with 0 points (and a low-frequency tone). The cutoff for a 'fast response' was calculated based on the practice block that directly preceeded the experimental blocks, as described above. Hence, the cutoff for a 'fast response' was tailored to an individual's own baseline reaction time, independent of reinforcement. The total points score remained on the screen throughout the task. On some trials, responses were not followed by any feedback and subjects could not win any points.

Immediately before the presentation of the circles stimulus, a colored border appeared ('color-cue'), signaling the probability of receiving reinforcement on the next trial. Two different color-cues were associated with 10\% (low) and $90 \%$ (high) reinforcement probability. A reference condition of $50 \%$ reinforcement probability (ie maximum uncertainty) was also included. Participants were told that there would be some relationship between the color-cues and the probability of reinforcement, but were not but were not informed of the contingencies explicitly. Instead, participants learnt the contingencies as the task progressed. Since the aim of the study was to examine motivated responding under conditions of high and low reinforcement probability, data indexing latency and accuracy were derived from the $10 \%$ reinforcement and $90 \%$ reinforcement conditions. The circles-stimulus was presented a variable interval after the presentation of the color-cue, so that the inter-stimulus interval remained constant at $2500 \mathrm{~ms}$. The stimulus remained on the screen until a response was made or until a 'too late' message was displayed (if a response was not made within $2000 \mathrm{~ms}$ of stimulus onset). Subjects were told that they had to obtain as many points as possible.

Following the test, subjects were given a de-brief questionnaire on which they indicated their estimate of reinforcement probability for each colour, using $10 \mathrm{~cm}$ analog scales. This provided a measure of participants' explicit awareness of stimulus-reinforcement contingencies. To perform the CRRT, all participants sat approximately $60 \mathrm{~cm}$ from a touch-sensitive computer screen controlled by an Advantech Pentium personal computer (Model PPC120T-RT).

\section{Statistical Analysis}

Data were analysed using SPSS 10 (SPSS Inc, Chicago, IL, USA). Mixed analysis of variance (ANOVA) was employed for this two-group within-subjects study. All tests were twotailed. Treatment $(\mathrm{TRP}+/ \mathrm{TRP}-)$ and time $\left(\mathrm{T}_{0} / \mathrm{T}_{5}\right)$ were entered as within-subjects factors in the analyses of plasma 
tryptophan levels and the ratio of tryptophan to the other large neutral amino acids ( LLNAA), the best peripheral indicator of brain tryptophan availability for 5-HT synthesis (Fernstrom and Wurtman, 1972). For CRRT data, treatment $(\mathrm{TRP}+/ \mathrm{TRP}-)$ and probability of reinforcement $(90 \% / 10 \%)$ were entered as within-subjects factors. Genotype group ( $l l$ or $s s)$ was entered as the between-subjects factor in all analyses. Treatment order (TRP + /TRP - or TRP -/TRP + ) was fully counterbalanced and was entered as additional between-subjects factor. However, if the main effect of order and interactions of order with treatment and/or genotype were found to be nonsignificant, data were collapsed across order for subsequent analyses. Gender was also initially entered as a between-subjects factor, but was removed if the main effect of gender and all interactions with gender were nonsignificant. Further analysis of simple effects and interaction effects were carried out by constructing appropriate ANOVAs for each comparison of interest. For these analyses, the MSerror term and degrees of freedom were taken from the interaction term of the omnibus ANOVA, as recommended in Howell (2002, pp 412-415). CRRT accuracy data were arcsine-transformed (2arcsinx) before analysis, as is appropriate whenever the variance of a measure is proportionate to its mean (Howell, 2002), though data presented are untransformed values for clarity. Correlational analyses between tryptophan: $\Sigma$ LNAA ratio were performed using the Spearman's Rank correlation coefficient, since the residuals from the regression were not normally distributed.

\section{RESULTS}

\section{Demographic Measures}

Demographic measures are reported in Table 1. The genotype groups did not differ in terms of age or NART IQ.

\section{Amino-Acid Concentrations}

Owing to difficulties with taking blood, plasma samples were not available for three participants at all four time points (one of the $l l$ genotype, two of the ss genotype). For plasma total tryptophan concentration an expected significant treatment $\times$ time interaction was evident $\left(\mathrm{F}_{1,25}=102.0, p<0.001\right)$. Simple effects analysis revealed that plasma total tryptophan concentration increased from $\mathrm{T}_{0}$ to $\mathrm{T}_{5}$ by $65 \%$ when TRP + was administered $\left(\mathrm{F}_{1,25}=49.2\right.$, $p<0.001$ ), but fell from $\mathrm{T}_{0}$ to $\mathrm{T}_{5}$ by $69 \%$ when TRPwas administered $\left(\mathrm{F}_{1,25}=52.1, p<0.001\right)$. This interaction was equivalent between the two genotype groups (treatment $\times$ time $\times$ genotype interaction: $\left.\mathrm{F}_{1,25}=1.1, p=0.3\right) . \mathrm{A}$ similar treatment $\times$ time interaction was present for tryptophan: $\Sigma$ LNAA ratio $\left(\mathrm{F}_{1,25}=114.1, p<0.001\right)$. Simple effects analysis revealed that tryptophan: $\Sigma$ LNAA ratio increased from $\mathrm{T}_{0}$ to $\mathrm{T}_{5}$ by $36 \%$ when TRP + was administered $\left(\mathrm{F}_{1,25}=27.9, p<0.001\right)$, but fell from $\mathrm{T}_{0}$ to $\mathrm{T}_{5}$ by $63 \%$ when TRP - was administered $\left(\mathrm{F}_{1,25}=95.8, p<0.001\right)$. Again, this interaction was equivalent between the two genotype groups (treatment $\times$ time $\times$ genotype interaction: $F_{1,25}<1$ ) (see Table 2). Plasma tryptophan concentrations and tryptophan: $\Sigma$ LNAA ratio were unaffected by gender following either TRP + or TRP $-(p>0.1$ for all interactions $)$.

\section{Cued-Reinforcement Reaction Time Task}

Data from the CRRT are presented in Figure 1 and Table 2. Analysis of latency data revealed a predicted treatment $\times$ reinforcement probability $\times$ genotype interaction $\left(\mathrm{F}_{1,26}=5.8, p=0.024\right)$. Analysis of simple main effects in the ss genotype group revealed that ss participants responded significantly more quickly on $90 \%$ reinforced

Table I Demographic Measures

\begin{tabular}{lccc}
\hline & II genotype & ss genotype & Statistic \\
\hline$N($ male $)$ & $15(8)$ & $15(9)$ & $\chi_{1}^{2}<1$ \\
Age & $29.2(9.0)$ & $24.3(5.0)$ & $t_{23.2}=1.8, p=N S$ \\
NART IQ & $\mid 15.1(6.2)$ & $117.0(7.3)$ & $t_{28}<1$ \\
\hline
\end{tabular}

Numbers represent mean values (SD).

Table 2 Plasma Tryptophan and Behavioral Measures

\begin{tabular}{|c|c|c|c|c|c|c|c|c|c|}
\hline \multirow{2}{*}{ Test } & \multirow{2}{*}{ Measure } & \multicolumn{4}{|c|}{ II genotype } & \multicolumn{4}{|c|}{ ss genotype } \\
\hline & & \multicolumn{2}{|c|}{ Placebo (TRP+) } & \multicolumn{2}{|c|}{ Depleted (TRP - ) } & \multicolumn{2}{|c|}{ Placebo (TRP+) } & \multicolumn{2}{|c|}{ Depleted (TRP - ) } \\
\hline \multicolumn{10}{|c|}{ Plasma tryptophan } \\
\hline & Total tryptophan $(\mu$ moles/l) & $43.3(20.1)$ & $77.9(51.6)$ & $49.4(13.6)$ & $19.1(14.4)$ & $43.2(21.3)$ & $74.3(47.1)$ & $44.8(19.8)$ & I7.2( $(0.9)$ \\
\hline \multicolumn{10}{|l|}{ CRRT } \\
\hline \multirow[t]{2}{*}{$10 \%$ reward } & Percent correct & & $88.3(8.1)$ & & $88.5(8.7)$ & & $88.3(9.0)$ & & $93.1(4.6)$ \\
\hline & Debrief probability rating & & $35.4(26.3)$ & & $27.7(29.8)$ & & $23.3(19.5)$ & & $24.9(25.0)$ \\
\hline \multirow[t]{2}{*}{$90 \%$ reward } & Percent correct & & $90.4(8.3)$ & & $87.9(6.5)$ & & $89.8(5.7)$ & & $92.1(6.0)$ \\
\hline & Debrief probability rating & & $75.4(13.3)$ & & $61.5(24.4)$ & & $66.0(21.6)$ & & $74.7(21.0)$ \\
\hline
\end{tabular}



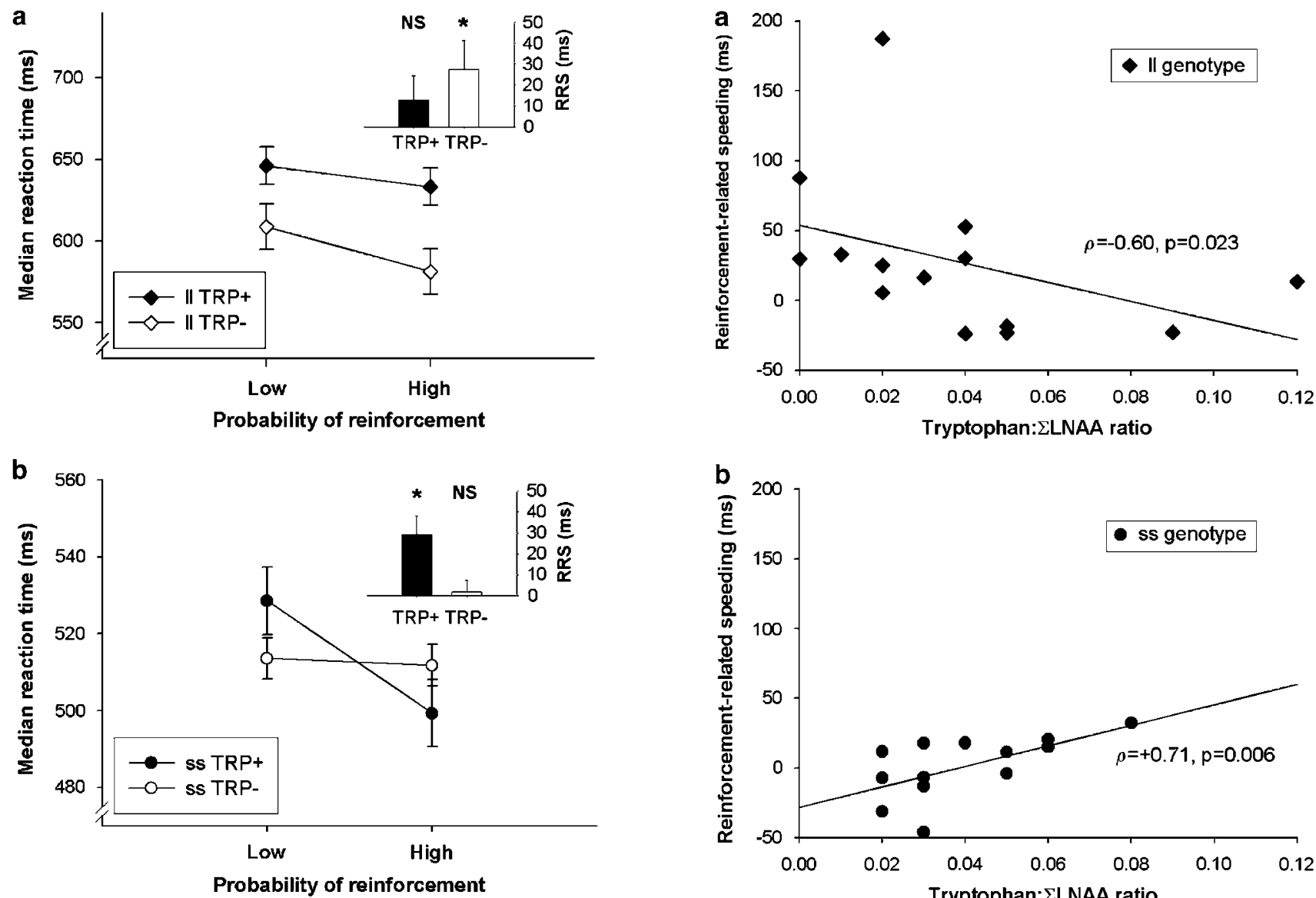

Figure I Median reaction time on the Cued-Reinforcement Reaction Time task for 90 and 10\% reinforced trials in (a) II and (b) ss volunteers under placebo (TRP + ) and tryptophan-depleted (TRP-) conditions (insets 'reinforcement-related speeding' (the difference in median reaction time between 90 and $10 \%$ probability of reinforcement conditions-RRS) for TRP + and TRP - conditions). The ss genotype group showed RRS following placebo, which was abolished following acute tryptophan depletion, while the II genotype group showed the opposite pattern of response. ${ }^{*} p<0.005$. Points and bars represent mean values, error bars I SED.

trials than $10 \%$ reinforced trials ('reinforcement-related speeding $-\mathrm{RRS})$ following TRP $+\left(\mathrm{F}_{1,26}=11.2, p<0.005\right)$. However, RRS was abolished following TRP- in the ss genotype group $\left(\mathrm{F}_{1,14}<1\right)$ (see Figure $\left.1 \mathrm{~b}\right)$. By contrast, the $l l$ genotype group showed significant RRS following TRP$\left(\mathrm{F}_{1,26}=9.9, p<0.005\right)$, but this was not the case following TRP $+\left(\mathrm{F}_{1,26}=2.1, p=0.16\right)$ (see Figure 1a).

The $l l$ genotype group responded significantly more quickly following TRP - than following TRP + , independent of reinforcement probability (treatment $\times$ genotype interaction: $\mathrm{F}_{1,26}=7.3, p=0.012$; effect of treatment in $l l$ group: $\left.\mathrm{F}_{1,26}=13.6, p<0.005\right)$. This effect did not occur in the ss genotype group $\left(\mathrm{F}_{1,26}<1\right)$. Over all conditions, the ss genotype group responded more quickly than the $l l$ genotype group $\left(\mathrm{F}_{1,26}=4.6, p=0.042\right)$. There was also a main effect of reinforcement probability, representing RRS independent of treatment or genotype $\left(\mathrm{F}_{1,26}=8.3\right.$, $p=0.008)$. Overall latency and RRS were unaffected by gender following either TRP + or TRP $-(p>0.1$ for all interactions).

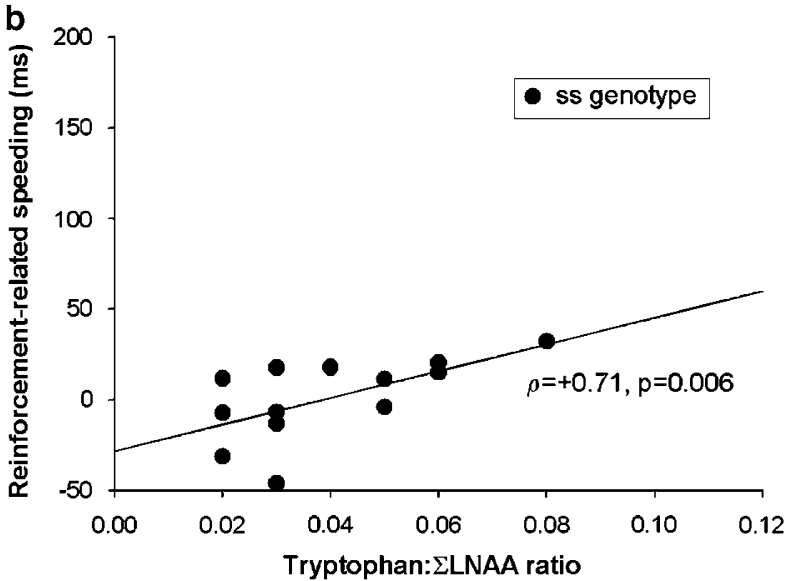

Figure 2 The relationship between 'reinforcement-related speeding' (the difference in median reaction time between 90 and $10 \%$ probability of reinforcement conditions-RRS) on the Cued-Reinforcement Reaction Time task and plasma tryptophan: $\Sigma$ large neutral amino acid (LNAA) ratio in the (a) II and (b) ss genotype groups following acute tryptophan depletion. In the ss genotype group there was a positive association between RRS and tryptophan: $\Sigma$ LNAA ratio $(p=0.006)$, whereas in the $\|$ genotype group the same association was negative $(p=0.023)$.

Analysis of accuracy data revealed a treatment $\times$ genotype interaction $\left(\mathrm{F}_{1,26}=5.0, p=0.034\right)$. Simple effects analysis indicated that participants in the ss genotype group made significantly fewer errors following TRP - than following TRP $+\left(\mathrm{F}_{1,26}=6.0, p=0.020\right)$, whereas treatment did not affect accuracy in the $l l$ genotype group $\left(\mathrm{F}_{1,26}<1\right)$. The main effects of treatment, reinforcement probability and genotype were all nonsignificant $(p>0.2)$, as was the treatment $\times$ reinforcement probability $\times$ genotype interaction $\left(\mathrm{F}_{1,26}<1\right)$. Accuracy was unaffected by gender either following TRP + or TRP $-(p>0.1$ for all interactions).

De-brief questionnaire data were not available on both occasions for two participants (both of the $l l$ genotype). Therefore the following analysis is based on data from 28 participants. Analysis of de-brief questionnaire data suggested that ATD did not affect participants' ability to learn the contingencies between the color-cues and their associated probability of reinforcement. Participants rated correct responses on trials on which there was a $90 \%$ probability of reinforcement as significantly more likely to result in points than those on which there was a $10 \%$ probability of reinforcement $\left(\mathrm{F}_{1,26}=60.5, p<0.001\right)$. There 
was no main effect of treatment and no interaction between reinforcement probability and genotype or between treatment, reinforcement probability and genotype $\left(\mathrm{F}_{1,26}<1\right.$ for all).

\section{Correlational Analyses}

In order to further explore the dissociation of responses to ATD on the CRRT between the ss and $l l$ genotype groups, the relationship between tryptophan: $\Sigma$ LNAA ratio and RRS was examined. Following TRP-, tryptophan: $\Sigma$ LNAA ratio was positively correlated with RRS in the ss genotype group $\left(\rho_{13}=0.71, p=0.006\right)$, whereas the same association was negative in the $l l$ genotype group $\left(\rho_{14}=-0.60, p=0.023\right)$ (see Figure 2).

\section{DISCUSSION}

These results demonstrate dissociable effects of ATD on motivationally speeded action in groups of different 5-HTTLPR genotypes. In the ss genotype group, ATD abolished speeding on trials with a very high probability of reinforcement relative to those with a very low probability of reinforcement (reinforcement-related speeding-RRS). In the $l l$ genotype group, by contrast, a significant RRS effect was present following ATD, but was attenuated and nonsignificant following placebo. The nature of the interaction effect was further clarified by opposite associations of RRS with plasma tryptophan: LNAA ratio, the best peripheral indicator of tryptophan availability to the brain for 5-HT synthesis (Fernstrom and Wurtman, 1972), between the two genotype groups (see Figure 2). The regression lines in Figure 2 suggest that RRS was impaired as a function of the extent of tryptophan depletion within the ss genotype group (Figure $2 \mathrm{~b}$ ), whereas the converse occurred within the $l l$ genotype group (Figure 2a). ATD did not affect participants' subjective ratings of the likelihood of receiving reinforcement in the different reinforcement probability conditions in either genotype group, making it unlikely that the ss participants were simply unaware of the stimulus-reinforcement contingencies following ATD. Importantly, the genotype groups did not differ in terms of plasma amino-acid levels following ATD. This implies that although the effect of ATD on plasma tryptophan levels was equivalent between the genotype groups (and by inference the effect on central 5-HT synthesis), the behavioral response elicited by this depletion was profoundly different. Finally, there were no gender specific effects of ATD on plasma amino-acid levels or behavioral response to ATD.

Consistent with our findings, a number of studies have demonstrated that the processing of affective cues and response to depletions of 5-HT differ according to genotype at the 5-HTTLPR. The $s$ allele has been associated with increased sensitivity to ATD in women (Neumeister et al, 2002), and recently Roiser et al (2005) reported that possession of the $s$ allele was associated with increased vulnerability to emotional disturbance following chronic ecstasy use, which is thought to result in 5-HT depletion (Green et al, 2003).

Two unexpected results of this study merit discussion. Firstly, individuals in the ss genotype group responded more quickly than individuals with the $l l$ genotype on the CRRT, and this speeded responding was independent of treatment condition and reinforcement probability. To our knowledge, this is the first time that differences between groups of healthy volunteers of different 5-HTTLPR genotypes have been reported on a behavioral test. The neural mechanisms underlying this speeding await clarification in future studies combining molecular genetics with functional brain imaging.

Secondly, the $l l$ genotype group exhibited attenuated and nonsignificant RRS under placebo conditions. While it is possible that this result could be due to low power, and the RRS effect might reach statistical significance in a larger sample, it might also be clarified by considering the effect of the placebo treatment in our study. While it was intended that the TRP + amino acid mixture would stabilise the plasma tryptophan: $\Sigma$ LNAA ratio over the course of the study day, it in fact led to an increase in the ratio at $\mathrm{T}_{5}$ relative to $\mathrm{T}_{0}$. Given the negative association of plasma tryptophan: $\Sigma$ LNAA ratio with RRS in volunteers carrying the $l l$ genotype, it is possible that the apparent absence of significant RRS in this group following TRP + was a result of increased 5-HT synthesis. By the same rationale, it is also possible that RRS may have been enhanced by increased 5-HT synthesis in the ss genotype group following the TRP + mixture. Consistent with this hypothesis, it has previously been reported that augmenting plasma tryptophan via dietary manipulation improved cognitive performance in healthy volunteers selected for stress-vulnerability/ neuroticism (a trait that has been associated with possession of the $s$ allele - see Lesch et al, 1996; Sen et al, 2004), but not in relatively stress-invulnerable volunteers (Markus et al, 2000, 2002).

These gene-related differential effects of tryptophan depletion on reward processing are consistent with the hypothesis that the $l l$ genotype is associated with higher serotonergic neurotransmission compared to the ss genotype under normal physiological conditions. While one might expect increased extracellular 5-HT levels in ss individuals due to the reduced efficiency of the 5-HT transporter, accumulating evidence suggests an association between the $l l$ genotype and enhanced serotonergic neurotransmission, possibly due to the long-term developmental effects of reduced 5-HT reuptake on cell number, firing rate and post-synaptic receptor sensitivity ( $\mathrm{Li}$ et al, 2000; Lira et al, 2003; David et al, 2005). We speculate that the relationship between serotonergic neurotransmission and incentive motivational processing may operate according to an 'inverted- $U$ ' function. The differential effects of ATD between the genotype groups suggest that augmenting 5-HT synthesis in the ss genotype group and inhibiting 5 -HT synthesis in the $l l$ genotype group have a similar functional effect-that is, modulating the physiological state of the brain reward system to optimize incentive motivational processing. Such models of the interaction between monoaminergic function and cognitive performance have previously been postulated for DA and NA (Williams and Goldman-Rakic, 1995; Zahrt et al, 1997; Aston-Jones et al, 1999).

The physiological and neurochemical substrates of reward processing are the focus of a large body of ongoing research, and the results of studies to date suggest 
that activity within amygdala/ventral striatum-ventromedial prefrontal cortex (VMPFC) circuitry is likely to play a central role (Everitt et al, 2003; O'Doherty, 2004). Using functional magnetic resonance imaging, Knutson and co-workers have investigated reward processing in humans using a speed-related reward paradigm similar to the CRRT. They demonstrated that the amygdalo-ventral striatal system, incorporating the nucleus accumbens (NAcc) and central nucleus of the amygdala (CeN), is activated during reinforcement anticipation, or the appetitive phase of reward processing (Knutson et al, 2001), even when subjects are familiar with stimulus-reward contingencies (Hommer et al, 2003). It is noteworthy that Hariri and co-workers have demonstrated that fearful faces generate increased amygdala activity in $s$ carriers relative to $l l$ homozygotes (Hariri et al, 2002, 2005), and a recent report described increased coupling between amygdala and VMPFC in $s$ carriers relative to $l l$ homozygotes (Heinz et al, 2005). This has important implications as a variety of evidence also supports a role for the VMPFC in the representation of reward outcome, or the consummatory phase of reward processing, both in humans (Elliott et al, 1999, 2003; Gehring and Willoughby, 2002; Knutson et al, 2003) and non-human primates (Schultz et al, 2000).

Whereas DA has traditionally been thought to be the neurotransmitter most implicated in modulating the activity of the brain reward systems (Berridge and Robinson, 1998; Cannon and Bseikri, 2004), the role of 5-HT and its interaction with the mesolimbic DA system in mediating incentive motivational processes has not been extensively investigated, despite the involvement of 5-HT in the reinforcing effects of cocaine and MDMA (Aronson et al, 1995; Bankson and Cunningham, 2001). The present study suggests that modulating 5-HT may impact on reward processing, possibly via interaction with the mesolimbic DA system. Furthermore, there is good evidence to suggest that the activity of the midbrain DA neurons, and accordingly activity in the terminal zones of their efferent projections, is contingent on intact 5-HT signaling (Minabe et al, 1996), and that stimulation of a variety of 5-HT receptors results in DA release in the NAcc (Schmidt et al, 1992; Hallbus et al, 1997; De Deurwaerdere et al, 1998; Yan, 2000; Yan and Yan, 2001; Minabe et al, 2004).

It is also possible that $5-\mathrm{HT}$ may affect reward processing independently of DA. 5-HT receptors are found throughout the brain reward systems (Brown and Molliver, 2000), and the presentation of reward-related cues has been shown to increase the concentration of 5-HIAA in the medial PFC in rats (Merali et al, 2004). 5-HT is also known to play a central role in depression, in which reward processing is disrupted, leading to the core symptom of anhedonia (Naranjo et al, 2001; Spitzer et al, 2002). It will be important in future studies to further investigate both the role of 5- $\mathrm{HT}$ and the nature of the interaction between 5-HT and DA in modulating reward processing; such research may further our understanding of how functional polymorphisms that alter the activity of the serotonin system affect both risk for affective disorders and individual responses to antidepressant medication (Caspi et al, 2003; Smits et al, 2004).

\section{Summary}

This study sought to investigate the relationship between 5-HTTLPR polymorphism and incentive motivational responses to ATD. It was predicted that possession of the ss genotype would be associated with increased vulnerability to a temporary reduction in 5-HT synthesis, demonstrating a loss of motivationally speeded action following ATD. In accordance with this prediction, ATD abolished RRS on the CRRT in the ss genotype group, whereas the $l l$ genotype group only exhibited significant RRS following ATD. Furthermore, the relationship between tryptophan availability to the brain and incentive motivation showed a striking dissociation between the two genotype groups; in the ss genotype group, reduced tryptophan: $\Sigma$ LNAA ratio was associated with impaired motivationally-speeded action, whereas in the $l l$ genotype group, reduced tryptophan: $\Sigma$ LNAA ratio was associated with improved motivationally speeded action. These data are consistent with findings that the $s$ allele is a risk-factor for affective disorders, and highlight the importance that genetic variation plays in determining individual responses to pharmacological manipulation. In particular the abolition of motivationally speeded action following ATD in individuals of the ss genotype relates to the core symptom of anhedonia in depression, and suggests that impaired motivation may play an important role in the development of major depression in carriers of the ss genotype.

\section{ACKNOWLEDGEMENTS}

This work was supported by a Wellcome Trust programme grant to TW Robbins, BJ Sahakian, BJ Everitt and AC Roberts (Number 019407) and was completed within the MRC Centre for Behavioural and Clinical Neuroscience. Many thanks to Caroline Humphries and all the staff at the Wellcome Trust Clinical Research Facility at Addenbrooke's Hospital, Cambridge for their help and support. BJ Sahakian holds the FC Donders Chair in Psychopharmacology at Utrecht University. DC Rubinsztein is a Wellcome Trust Senior Fellow in Clinical Science. JP Roiser was supported by an MRC studentship. We thank Dr M Franklin and Dr J Odontiadis (University of Oxford) for analysis of plasma data and Dr J Whitaker for DNA extraction.

\section{REFERENCES}

Aronson SC, Black JE, McDougle CJ, Scanley BE, Jatlow P, Kosten TR et al (1995). Serotonergic mechanisms of cocaine effects in humans. Psychopharmacology (Berlin) 119: 179-185.

Aston-Jones G, Rajkowski J, Cohen J (1999). Role of locus coeruleus in attention and behavioral flexibility. Biol Psychiatry 46: $1309-1320$.

Bankson MG, Cunningham KA (2001). 3,4-Methylenedioxymethamphetamine (MDMA) as a unique model of serotonin receptor function and serotonin-dopamine interactions. $J$ Pharmacol Exp Ther 297: 846-852.

Beck AT, Ward CH, Medelson M, Erbaugh J (1961). An inventory for measuring depression. Arch Gen Psychiatry 4: 561-571.

Berridge KC, Robinson TE (1998). What is the role of dopamine in reward: hedonic impact, reward learning, or incentive salience? Brain Res Brain Res Rev 28: 309-369. 
Brown P, Molliver ME (2000). Dual serotonin (5-HT) projections to the nucleus accumbens core and shell: relation of the 5-HT transporter to amphetamine-induced neurotoxicity. J Neurosci 20: $1952-1963$.

Cannon CM, Bseikri MR (2004). Is dopamine required for natural reward? Physiol Behav 81: 741-748.

Caspi A, Sugden K, Moffitt TE, Taylor A, Craig IW, Harrington H et al (2003). Influence of life stress on depression: moderation by a polymorphism in the 5-HTT gene. Science 301: 386-389.

Cools R, Blackwell A, Clark L, Menzies L, Cox S, Robbins TW (2005). Tryptophan depletion disrupts the motivational guidance of goal-directed behavior as a function of trait impulsivity. Neuropsychopharmacology 30: 1362-1373.

David SP, Murthy NV, Rabiner EA, Munafo MR, Johnstone EC, Jacob $\mathrm{R}$ et al (2005). A functional genetic variation of the serotonin $(5-\mathrm{HT})$ transporter affects $5-\mathrm{HT} 1 \mathrm{~A}$ receptor binding in humans. J Neurosci 25: 2586-2590.

De Deurwaerdere P, Stinus L, Spampinato U (1998). Opposite change of in vivo dopamine release in the rat nucleus accumbens and striatum that follows electrical stimulation of dorsal raphe nucleus: role of 5-HT3 receptors. J Neurosci 18: 6528-6538.

Delgado PL, Charney DS, Price LH, Aghajanian GK, Landis H, Heninger GR (1990). Serotonin function and the mechanism of antidepressant action. Reversal of antidepressant-induced remission by rapid depletion of plasma tryptophan. Arch Gen Psychiatry 47: 411-418.

Elliott R, Newman JL, Longe OA, Deakin JF (2003). Differential response patterns in the striatum and orbitofrontal cortex to financial reward in humans: a parametric functional magnetic resonance imaging study. J Neurosci 23: 303-307.

Elliott R, Rees G, Dolan RJ (1999). Ventromedial prefrontal cortex mediates guessing. Neuropsychologia 37: 403-411.

Everitt BJ, Cardinal RN, Parkinson JA, Robbins TW (2003). Appetitive behavior: impact of amygdala-dependent mechanisms of emotional learning. Ann N Y Acad Sci 985: 233-250.

Fernstrom JD, Wurtman RJ (1972). Brain serotonin content: physiological regulation by plasma neutral amino acids. Science 178: $414-416$.

Furlong RA, Ho L, Walsh C, Rubinsztein JS, Jain S, Paykel ES et al (1998). Analysis and meta-analysis of two serotonin transporter gene polymorphisms in bipolar and unipolar affective disorders. Am J Med Genet 81: 58-63.

Furst P, Pollack L, Graser TA, Godel H, Stehle P (1990). Appraisal of four pre-column derivatization methods for the highperformance liquid chromatographic determination of free amino acids in biological materials. J Chromatogr 499: 557-569.

Gehring WJ, Willoughby AR (2002). The medial frontal cortex and the rapid processing of monetary gains and losses. Science 295: 2279-2282.

Green AR, Mechan AO, Elliott JM, O'Shea E, Colado MI (2003). The pharmacology and clinical pharmacology of 3,4-methylenedioxymethamphetamine (MDMA, "ecstasy"). Pharmacol Rev 55: 463-508.

Hallbus M, Magnusson T, Magnusson O (1997). Influence of $5-\mathrm{HT} 1 \mathrm{~B} / 1 \mathrm{D}$ receptors on dopamine release in the guinea pig nucleus accumbens: a microdialysis study. Neurosci Lett 225: 57-60.

Hariri AR, Drabant EM, Munoz KE, Kolachana BS, Mattay VS, Egan MF et al (2005). A susceptibility gene for affective disorders and the response of the human amygdala. Arch Gen Psychiatry 62: $146-152$.

Hariri AR, Mattay VS, Tessitore A, Kolachana B, Fera F, Goldman $\mathrm{D}$ et al (2002). Serotonin transporter genetic variation and the response of the human amygdala. Science 297: 400-403.

Harrison AA, Liem YT, Markou A (2001). Fluoxetine combined with a serotonin-1A receptor antagonist reversed reward deficits observed during nicotine and amphetamine withdrawal in rats. Neuropsychopharmacology 25: 55-71.
Heils A, Teufel A, Petri S, Stober G, Riederer P, Bengel D et al (1996). Allelic variation of human serotonin transporter gene expression. J Neurochem 66: 2621-2624.

Heinz A, Braus DF, Smolka MN, Wrase J, Puls I, Hermann D et al (2005). Amygdala-prefrontal coupling depends on a genetic variation of the serotonin transporter. Nat Neurosci 8: 20-21.

Hommer DW, Knutson B, Fong GW, Bennett S, Adams CM, Varnera JL (2003). Amygdalar recruitment during anticipation of monetary rewards: an event-related fMRI study. Ann NY Acad Sci 985: 476-478.

Howell DC (2002). Statistical Methods for Psychology, 5th edn. Duxbury Press: London.

Knutson B, Adams CM, Fong GW, Hommer D (2001). Anticipation of increasing monetary reward selectively recruits nucleus accumbens. J Neurosci 21: RC159.

Knutson B, Fong GW, Bennett SM, Adams CM, Hommer D (2003). A region of mesial prefrontal cortex tracks monetarily rewarding outcomes: characterization with rapid event-related fMRI. Neuroimage 18: 263-272.

Lesch KP, Bengel D, Heils A, Sabol SZ, Greenberg BD, Petri S et al (1996). Association of anxiety-related traits with a polymorphism in the serotonin transporter gene regulatory region. Science 274: 1527-1531.

Leyton M, Ghadirian AM, Young SN, Palmour RM, Blier P, Helmers KF et al (2000). Depressive relapse following acute tryptophan depletion in patients with major depressive disorder. J Psychopharmacol 14: 284-287.

Li Q, Wichems C, Heils A, Lesch KP, Murphy DL (2000). Reduction in the density and expression, but not G-protein coupling, of serotonin receptors (5-HT1A) in 5-HT transporter knock-out mice: gender and brain region differences. J Neurosci 20: 78887895.

Lira A, Zhou M, Castanon N, Ansorge MS, Gordon JA, Francis JH et al (2003). Altered depression-related behaviors and functional changes in the dorsal raphe nucleus of serotonin transporterdeficient mice. Biol Psychiatry 54: 960-971.

Lott DC, Kim SJ, Cook Jr EH, de Wit H (2005). Dopamine transporter gene associated with diminished subjective response to amphetamine. Neuropsychopharmacology 30: 602-609.

Markus CR, Olivier B, de Haan EH (2002). Whey protein rich in alpha-lactalbumin increases the ratio of plasma tryptophan to the sum of the other large neutral amino acids and improves cognitive performance in stress-vulnerable subjects. Am J Clin Nutr 75: 1051-1056.

Markus R, Panhuysen G, Tuiten A, Koppeschaar H (2000). Effects of food on cortisol and mood in vulnerable subjects under controllable and uncontrollable stress. Physiol Behav 70: 333-342.

Mattay VS, Goldberg TE, Fera F, Hariri AR, Tessitore A, Egan MF et al (2003). Catechol $O$-methyltransferase val158-met genotype and individual variation in the brain response to amphetamine. Proc Natl Acad Sci USA 100: 6186-6191.

Merali Z, McIntosh J, Anisman H (2004). Anticipatory cues differentially provoke in vivo peptidergic and monoaminergic release at the medial prefrontal cortex. Neuropsychopharmacology 29: 1409-1418.

Minabe Y, Emori K, Ashby Jr CR (1996). The depletion of brain serotonin levels by para-chlorophenylalanine administration significantly alters the activity of midbrain dopamine cells in rats: an extracellular single cell recording study. Synapse 22: $46-53$.

Minabe Y, Shirayama Y, Hashimoto K, Routledge C, Hagan JJ, Ashby Jr CR (2004). Effect of the acute and chronic administration of the selective 5-HT6 receptor antagonist SB-271046 on the activity of midbrain dopamine neurons in rats: an in vivo electrophysiological study. Synapse 52: 20-28.

Moreno FA, Rowe DC, Kaiser B, Chase D, Michaels T, Gelernter J et al (2002). Association between a serotonin transporter 
promoter region polymorphism and mood response during tryptophan depletion. Mol Psychiatry 7: 213-216.

Naranjo CA, Tremblay LK, Busto UE (2001). The role of the brain reward system in depression. Prog Neuropsychopharmacol Biol Psychiatry 25: 781-823.

Neumeister A, Konstantinidis A, Stastny J, Schwarz MJ, Vitouch O, Willeit $\mathrm{M}$ et al (2002). Association between serotonin transporter gene promoter polymorphism (5HTTLPR) and behavioral responses to tryptophan depletion in healthy women with and without family history of depression. Arch Gen Psychiatry 59: 613-620.

O'Doherty JP (2004). Reward representations and reward-related learning in the human brain: insights from neuroimaging. Curr Opin Neurobiol 14: 769-776.

Reist C, Mazzanti C, Vu R, Tran D, Goldman D (2001). Serotonin transporter promoter polymorphism is associated with attenuated prolactin response to fenfluramine. Am J Med Genet 105: 363-368.

Rogers RD, Tunbridge EM, Bhagwagar Z, Drevets WC, Sahakian BJ, Carter CS (2003). Tryptophan depletion alters the decisionmaking of healthy volunteers through altered processing of reward cues. Neuropsychopharmacology 28: 153-162.

Roiser JP, Cook LJ, Cooper JD, Rubinsztein DC, Sahakian BJ (2005). Association of a functional polymorphism in the serotonin transporter gene with abnormal emotional processing in ecstasy users. Am J Psychiatry 162: 609-612.

Sasaki-Adams DM, Kelley AE (2001). Serotonin-dopamine interactions in the control of conditioned reinforcement and motor behavior. Neuropsychopharmacology 25: 440-452.

Schmidt CJ, Fadayel GM, Sullivan CK, Taylor VL (1992). 5-HT2 receptors exert a state-dependent regulation of dopaminergic function: studies with MDL 100,907 and the amphetamine analogue, 3,4-methylenedioxymethamphetamine. Eur J Pharmacol 223: 65-74.

Schultz W, Tremblay L, Hollerman JR (2000). Reward processing in primate orbitofrontal cortex and basal ganglia. Cereb Cortex 10: $272-284$.

Sen S, Burmeister M, Ghosh D (2004). Meta-analysis of the association between a serotonin transporter promoter polymorphism (5-HTTLPR) and anxiety-related personality traits. Am J Med Genet 127B: 85-89.
Smeraldi E, Zanardi R, Benedetti F, Di Bella D, Perez J, Catalano M (1998). Polymorphism within the promoter of the serotonin transporter gene and antidepressant efficacy of fluvoxamine. Mol Psychiatry 3: 508-511.

Smith GS, Lotrich FE, Malhotra AK, Lee AT, Ma Y, Kramer E et al (2004). Effects of serotonin transporter promoter polymorphisms on serotonin function. Neuropsychopharmacology 29: 2226-2234.

Smith KA, Fairburn CG, Cowen PJ (1997). Relapse of depression after rapid depletion of tryptophan. Lancet 349: 915-919.

Smits KM, Smits LJ, Schouten JS, Stelma FF, Nelemans P, Prins MH (2004). Influence of SERTPR and STin2 in the serotonin transporter gene on the effect of selective serotonin reuptake inhibitors in depression: a systematic review. Mol Psychiatry 9: 433-441.

Spitzer MB, Gibbon M, Williams JBW (2002). Stuctured Clinical Interview for DSM-IV-TR, Research Version, Patient Edition. $(S C I D-I / P)$. Biometrics Research, New York State Biometrics Institute: New York.

Whale R, Quested DJ, Laver D, Harrison PJ, Cowen PJ (2000). Serotonin transporter (5-HTT) promoter genotype may influence the prolactin response to clomipramine. Psychopharmacology (Berlin) 150: 120-122.

Williams GV, Goldman-Rakic PS (1995). Modulation of memory fields by dopamine D1 receptors in prefrontal cortex. Nature 376: $572-575$.

Yan QS (2000). Activation of 5-HT2A/2C receptors within the nucleus accumbens increases local dopaminergic transmission. Brain Res Bull 51: 75-81.

Yan QS, Yan SE (2001). Activation of 5-HT(1B/1D) receptors in the mesolimbic dopamine system increases dopamine release from the nucleus accumbens: a microdialysis study. Eur J Pharmacol 418: 55-64.

Young SN, Smith SE, Pihl RO, Ervin FR (1985). Tryptophan depletion causes a rapid lowering of mood in normal males. Psychopharmacology (Berlin) 87: 173-177.

Zahrt J, Taylor JR, Mathew RG, Arnsten AF (1997). Supranormal stimulation of D1 dopamine receptors in the rodent prefrontal cortex impairs spatial working memory performance. J Neurosci 17: 8528-8535. 